\title{
Post radiation evolution of giant virchow-robin spaces in a case of pituitary macroadenoma
}

Sir,

The term Virchow-Robin (VR) spaces or perivascular spaces is used to describe spaces around penetrating arteries containing interstitial fluid and which are lined by pial cells. They are most commonly located in the region of the lenticulostriate arteries in basal ganglia, along perforating arteries in high frontal region and in the brainstem around the midbrain. Most are $<1 \mathrm{~cm}$ in size and those more than $1.5 \mathrm{~cm}$ are termed as giant VR spaces. On imaging, they are seen to have sharp thin margins, normal brain parenchyma surrounding it, following cerebrospinal fluid density and showing no postcontrast enhancement. ${ }^{[1,2]}$ They are primarily asymptomatic but are known to be associated with presentation in the form of headache, dizziness, dementia, syncope, seizures, etc. The precise etiology of these lesions is not well known. No previous association of giant VR spaces with prior exposure to radiation has been reported in the available literature.

A 45-year-old gentleman presented to our institute in 2002 with complaints of large joint pains, joint swelling, coarsening of facial features, and hoarseness of voice of 2 years duration. On clinical, biochemical, and imaging evaluation, he was diagnosed to have a pituitary adenoma, secreting growth hormone. He underwent trans-sphenoidal surgery in 2002 and was on clinical and imaging follow-up when recurrent lesion was noted in 2007. He underwent a second surgery in 2007 and was advised postsurgical radiotherapy, which he initially declined. He was continued on follow-up and in 2011 he underwent radiotherapy for the residual lesion. Since then he has been on conservative clinical and imaging follow-up and remains asymptomatic.

Follow-up imaging done in 2016 [Figure 1] revealed giant VR spaces in their typical location in bilateral basal ganglia region with normal surrounding parenchyma without postcontrast enhancement or mass effect. On review of the previous available images in the form of magnetic resonance imaging (MRI) done in 2002, 2008, 2010 and computed tomography done in 2004, no evidence of prominent VR spaces was seen. The long follow-up period of 8 years prior to radiation was unremarkable but in 5 years after radiation the patient developed these cystic lesions. This
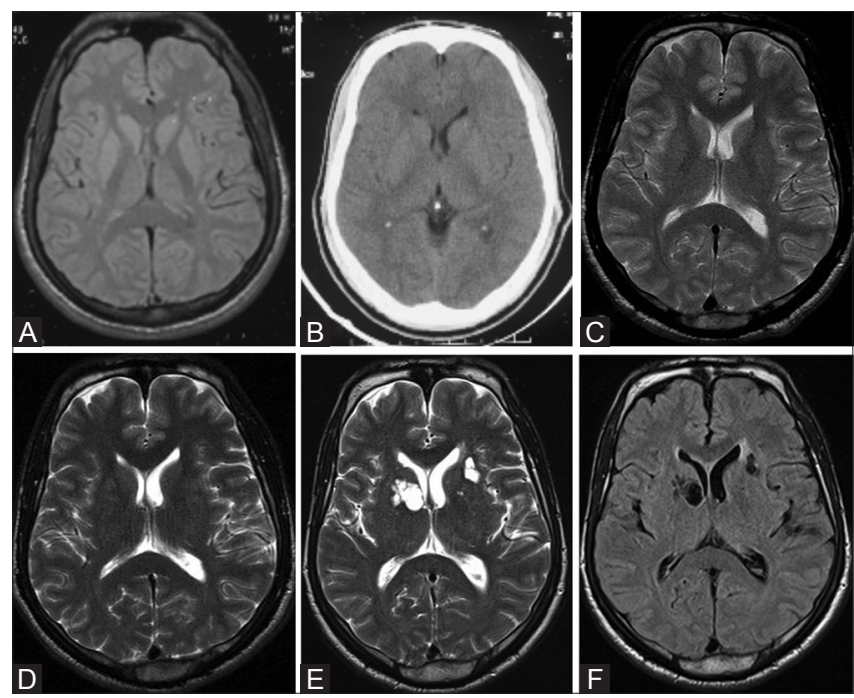

Figure 1 (A-F): Serial chronological images at level of basal ganglia (A) MRI- FLAIR Axial 2002 (B) NCCT- Axial 2004 (C) MRI- T2 Axial 2008 (D) MRI- T2 Axial 2010 (E) MRI- T2 Axial 2016 (F) MRI- FLAIR Axial 2016

temporal evolution of findings with history of exposure to radiation in the interim lead us to hypothesize the possibility of association of these newly evolved giant VR spaces to radiation exposure. Such an association has hitherto not been reported in the literature. White matter changes following radiation has been well documented in the literature and cystic changes have also encountered on long follow-up. ${ }^{[3-5]}$ However, correlation with evolution of VR spaces has not been suggested. We hypothesize that the dilated VR spaces seen in our case could be a finding due to postradiation white matter atrophy, and the temporal profile of evolution of MRI findings supports this hypothesis.

Financial support and sponsorship

Nil.

\section{Conflicts of interest}

There are no conflicts of interest.

Manoj Gopinath, Chinmay Nagesh, Chandrasekhar Kesavadas

Department of Imaging Sciences and Interventional Radiology, Sree Chitra Tirunal Institute for Medical Sciences and Technology, Trivandrum, Kerala, India E-mail: mangof2@rediffmail.com 


\section{References}

1. Tsutsumi S, Ito M, Yasumoto $Y$, Tabuchi T, Ogino I. The Virchow-Robin spaces: Delineation by magnetic resonance imaging with considerations on anatomofunctional implications. Childs Nerv Syst 2011;27:2057-66.

2. Kwee RM, Kwee TC. Virchow-Robin spaces at MR imaging. RadioGraphics 2007;27:1071-86.

3. Wang Y-XJ, King AD, Zhou H, Leung S-F, Abrigo J, Chan Y-L, et al. Evolution of radiation-induced brain injury: MR imaging-based study. Radiology 2010;254:210-8.

4. Brandsma D, van Helvoirt R, Taphoorn MJ. Multiple cysts in the cerebral white matter: A rare complication of whole brain radiation therapy. J Neurooncol 2001;53:51-4.

5. Tsuruda JS, Kortman KE, Bradley WG, Wheeler DC, Van Dalsem W, Bradley TP. Radiation effects on cerebral white matter: MR evaluation. AJR Am J Roentgenol 1987;149:165-71.
This is an open access journal, and articles are distributed under the terms of the Creative Commons Attribution-NonCommercial-ShareAlike 4.0 License, which allows others to remix, tweak, and build upon the work non-commercially, as long as appropriate credit is given and the new creations are licensed under the identical terms.

\begin{tabular}{|l|l|}
\hline \multicolumn{2}{|c|}{ Access this article online } \\
\hline Quick Response Code: & Website: \\
& www.ijri.org \\
\hline & \\
\cline { 2 - 2 } & Dol: \\
\hline
\end{tabular}

Cite this article as: Gopinath $\mathrm{M}$, Nagesh $\mathrm{C}$, Kesavadas $\mathrm{C}$. Post radiation evolution of giant virchow-robin spaces in a case of pituitary macroadenoma. Indian J Radiol Imaging 2018;28:373-4.

๑) 2018 Indian Journal of Radiology and Imaging | Published by Wolters Kluwer - Medknow 